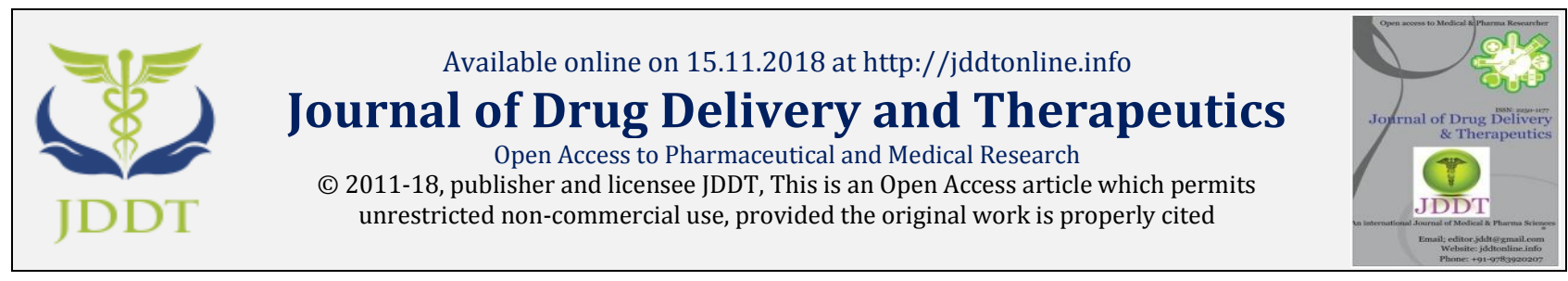

Open $\odot$ Access

Review Article

\title{
Electronic delivery of nicotine: help in smoking cessation or an alternative means of addiction
}

\author{
Bhyan Bhupinder ${ }^{1 *}$, Jangra Sarita ${ }^{2}$ \\ 1) *Department of Pharmaceutics, NIMS Institute of Pharmacy, NIMS University, Jaipur (Raj.) 303121, India. \\ 2) Department of Pharmacy Practice, NIMS Institute of Pharmacy, NIMS University, Jaipur (Raj.) 303121, India.
}

\begin{abstract}
All over the world currently there are billions of people who use tobacco regularly that's why now these days the tobacco is one of the most widely used drug. Many of scientific evidences reveal that tobacco is dangerous to human health. Tobacco contains plethora of harmful chemical substances, out of which many of them are carcinogens. Smoking is responsible for $90 \%$ of all lung cancer and mouth cancer, $75 \%$ of chronic bronchitis and emphysema and $25 \%$ of ischemic heart disease cases so tobacco is one of the leading preventable causes of deaths. In consideration of all these factors this review discusses various aspects of these electronic cigarettes like their structural components, working mechanism and their role in smoking cessation. E-cigarettes now gained a lot of popularity. This review also helps to aware health care professionals along with general population about the safety, myths, future challenges and about all pros and cons of using E-cigarettes.
\end{abstract}

Keywords: Cigarettes, electronic cigarettes, e-cigarettes, nicotine, public health, smoking cessation, tobacco

Article Info: Received 03 Oct, 2018; Review Completed 06 Nov 2018; Accepted 09 Nov 2018; Available online 15 Nov 2018

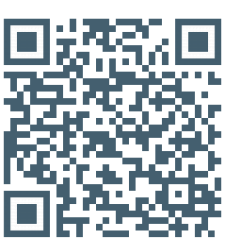

Cite this article as:

Bhyan B, Jangra S, Electronic delivery of nicotine: help in smoking cessation or an alternative means of addiction, Journal of Drug Delivery and Therapeutics. 2018; 8(6):356-359 DOI: http://dx.doi.org/10.22270/jddt.v8i6.2045

*Address for Correspondence:

Bhupinder Bhyan, Department of Pharmaceutics, NIMS Institute of Pharmacy, NIMS University, Jaipur, 303121, India.

\section{INTRODUCTION}

The fact that existence of tobacco in human life is from many last centuries which cannot be denied and became possible due to the addiction causing property of tobacco. Various conventional forms of tobacco like cigarettes, cigar and chewable tobacco as dip or snuff are delivering nicotine and many other harmful chemicals into the human body. Heavy intake of tobacco causes accumulative health problems that can lead to death no matter how tobacco was taken ${ }^{1}$. Chemical present in the smoke of tobacco are responsible of causing lung, throat, mouth cancer, as well as emphysema, chronic bronchitis, various heart problems, tooth decay, gum disease (gingivitis). Even these harmful chemicals are not only the threat to the life of those who are smoking but also very dangerous to the progeny of the smokers because these chemicals bind to human DNA and cause mutations that complicates over time. In fact, tobacco is one of the leading preventable causes of death in the world, according to a report by the center of disease control. Nicotine is present in all the tobacco products and is highly addictive. As the bioavailability of nicotine is very high, within very short period of time nicotine reaches to brain. It stimulates the brain for the production adrenaline which in turn causes a buzz of pleasure and energy. With this wish of pleasure and energy again, tobacco user become dependent and develop a high tolerance to tobacco. Tobacco also causes may withdrawal effects like increased appetite and weight gain, constipation, headache, anxiety, irritability, stress, nausea and insomnia. So in present scenario smoking cessation is of great concern in reference to public health. In smoking cessation e-cigarettes are now very popular ${ }^{2}$.

The first E-cigarette was invented in 2003 by a Chinese pharmacist Hon Lik as a means to quit smoking. Presently electronic nicotine cigarettes (ENC) are available in hundreds of different brands and models, along with many of different liquid formulations sold in cartridges or in small refill bottles. In January 2014, Zhu et al. conducted a study in a US and observed 466 brands of devices and 7,764 unique flavors advertised on the internet 3 . Flavors include tobacco and many others claiming as having the characteristics of fruits, sweets, drinks (coffee, alcoholic beverages 4,5. Different brands also vary in amount of nicotine delivered per puff i.e. $0 \mu \mathrm{g}$ to $35 \mu \mathrm{g}$ and the accuracy of labeling of nicotine content 6,7 . The market of ENC has shown a tremendous growth 
over the last few years. Users of e-cigarettes are now these days increasing at very high rate worldwide, with the result retail sales are expected to reach US $\$ 5$ billion by the end of 2016 .

\section{STRUCTURAL COMPONENTS}

Electronic cigarettes are novel type of nicotine delivery system which helps the user to inhale the vaporized nicotine. These electronic cigarettes are also known as ecigarettes, vapes. These E-cigarettes are very similar in size and structure of normal conventional tobacco cigarettes. There are basically four main parts of Ecigarettes. The first is the mouth piece, this part of the Ecigarettes enable the user to inhale vaporized nicotine by holding it in between the lips. The second is the replaceable cartridge that contains the liquid mixture of nicotine, propylene glycol or vegetable glycerin and flavoring agents. Third part of the device is responsible for heating the liquid mixture and turns it into vapors, is called as atomizer. The fourth and the last part of the Ecigarettes is battery which supplies power to the heating element for the vaporization of liquid mixture.

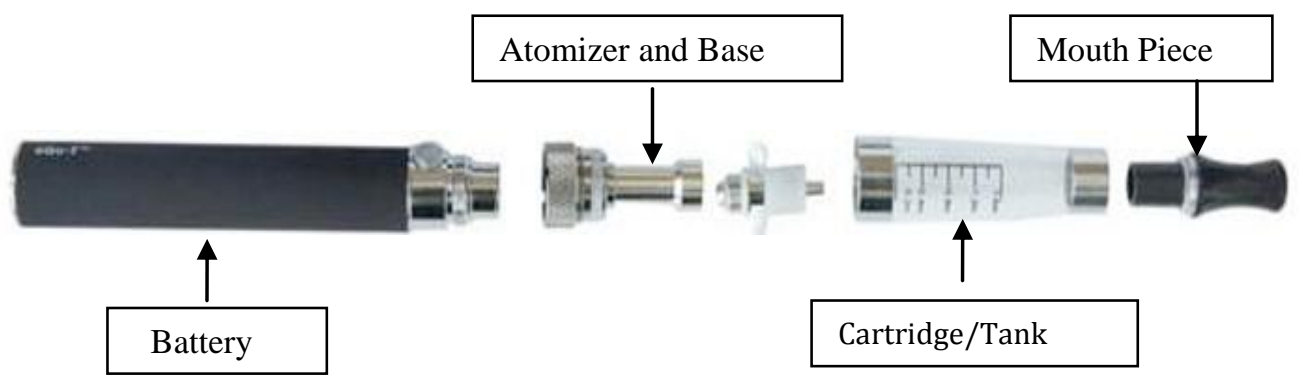

Figure 1: Different components of Electronic Nicotine Cigarette (ENC)

\section{WORKING MECHANISM}

Cartridge filled with liquid mixture of nicotine, propylene glycol, vegetable glycerol, water, ethanol, flavoring agents is assembled with the all other parts of ENC. Then activation of EN-cigarette can be done by pressing the button or by applying the suction as desired by the user 810. By the activation heating of liquid mixture starts which leads to the vaporization of components of liquid mixture and ultimately inhaled by the user.

\section{ROLE OF E-CIGARETTES IN SMOKING CESSATION}

In smoking cessation treatment various medications such as nicotine replacement therapies are in use and effective also, but long-term quit rates are around one in eight smokers which is very low 11,12 . The key of reducing the harmful effects of tobacco is eliminating the inhalation of the combustion products generated when tobacco is burned at high temperatures

The most common method of consuming tobacco is by burning which is also called smoking. Burning of tobacco in the form conventional tobacco cigarettes releases many deadly chemicals like tar which get inhaled while smoking [13. Use of ENCs eliminates many of these chemicals, because burning of tobacco is replaced with vaporization of nicotine. Hence ENC are the less harmful. E-cigarettes also reduces the risk of others inhaling secondhand smoke. Because e-cigs only emit vapor when they are exhaled, the amount of exposure other people receive is significantly less than when a traditional cigarette is smoked. Smokers use ENC for different reasons but the most widely reported ones are for smoking cessation, to cut down the number of cigarettes smoked per day, and to use a product that is perceived as being 'healthier' than conventional cigarettes 14,15 .

According to studies in three different countries related to ENCs from 2010 - 2013 shown that ENCs were capable of reducing tobacco dependence and withdrawal symptoms 16-21. Some other small non-randomised studies also revealed that conventional cigarettes quit rates ranging from $22 \%$ to $49 \%$ using EC 22,23 . Similar evidence from many randomized controlled studies reflects that nicotine ENCs help smokers quit long term, compared with placebo ENCs ${ }^{24}$ and also concluded the ability of ENCs are similar to that of nicotine patches 25 in smoking cessation.

\section{DILEMMA ABOUT ENC}

\section{Pros of using ENC}

Regarding the exposure to toxic chemicals, the use of ENC is considered as much safer than that of the conventional cigarettes. Primarily, an ENC vapor does not contain tar, carbon monoxide, nor most of the injurious chemicals found in cigarette smoke 26-28. Authorized body of England Public Heath has reported in its latest report that ENCs are $95 \%$ safer than normal tobacco cigarettes. On the other hand some of studies have identified the presence of toxic substance in ENCs and these findings have attracted wide media coverage 29 . But the presence of the toxic chemicals in ENC is 9 to 1,000 times lower which is slightly more harmful than pharmaceutical grade nicotine products used in NRT 30. A study have also shown that patient using ENC have improved lung functions and also reported many other health benefits as compared to those who continue use normal cigarettes. These health benefits in patients using ENCs are due to less smoke inhaled ${ }^{31}$.

\section{Cons of using ENC}

The FDA found low levels of nicotine in 17 (94\%) of 18 of the cartridges tested through a laboratory analysis conducted in US ${ }^{32}$. As nicotine is present in e-cigarettes and cigarettes, these are highly addictive means of inhaling nicotine. In addition to nicotine, although ENC do not produce tobacco smoke, they contain other potentially toxic chemicals, including formaldehyde and acetaldehyde ${ }^{33}$. Furthermore, the long- term health 
consequences of e-cigarette use till remain unpredictable. According the FDA conducted analytical studies ENCs were positive for carcinogenic and toxic chemicals such as diethylene glycol, formaldehyde and acetaldehyde. The FDA Center for Drug Evaluation and Research has not deemed E-cigarettes to be safe and effective for helping smokers to quit ${ }^{34}$. In 2013, the ALA reports that $76.8 \%$ of consumers use e-cigarettes and were found to also smoke conventional cigarettes simultaneously, instead of quitting 35. A study published by the American Heart Association (AHA) in Mayo Clinic Proceedings, stated that clinicians not recommend e-cigarettes as initial cessation aids. But, if primary smoking cessation method fails consumer can choose ENCs as an aid for quitting. No level of tobacco exposure is safe. Smoking cessation should always be recommended.

Recent in vitro studies by Barrington-Trimis et al published in a Journal of the American Medical Association suggest that the cytotoxic effects of e-liquids were largely because of flavoring agents 36 . The ALA study found " the number of middle and high school students who used e-cigarettes but never smoked a cigarette has increased to an alarming level" The study also found that these youths were almost 2 times more likely to intend to begin smoking regular cigarettes compared with youths who had never used ecigarettes. ${ }^{9}$ has voiced concerns about e-cigarettes being a "gateway" to conventional cigarettes ${ }^{5}$ and has referred to

\section{REFERENCES}

1. Shaik B, Tepoju M. A cross sectional community based study on the prevalence of tobacco smoking (considering only cigarette and hookah smoking) among the urban youth. AP J Psychol Med 2013; 14:164-70.

2. Prabhat J, Richard P. Global Effects of Smoking, of Quitting, and of Taxing Tobacco. N Engl J Med 2014; 370:60-8.

3. Zhu SH, Sun JY, Bonnevie E. Four hundred and sixty brands of e-cigarettes and counting: implications for product regulation. Tob Control 2014; 23:3-9.

4. Farsalinos K, Romagna G, Tsiapras D. Impact of flavour variability on electronic cigarette use experience: an internet survey. Int J Environ Res Public Health 2013; 10:7272-7282.

5. Goniewicz ML, Kuma T, Gawron M et al. Nicotine levels in electronic cigarettes. Nicotine \& Tobacco Research 2013; 15:158-166.

6. Goniewicz ML, Hajek P \& McRobbie H. Nicotine content of electronic cigarettes, its release in vapour and its consistency across batches: regulatory implications. Addiction 2014; 109:500-507.

7. Orr KK, Asal NJ. Efficacy of electronic cigarettes for smoking cessation. Annals of Pharmacotherapy 2014; 48:15021506.

8. Adriaens K, Van Gucht D, Declerck P et al. Effectiveness of the electronic cigarette: an eight-week Flemish study with six-month follow-up on smoking reduction, craving and experienced benefits and complaints. Int J Environ Res Public Health 2014; 11:11220-11248.

9. Farsalinos K, Romagna G, Tsiapras D et al. Evaluation of electronic cigarette use (vaping) topography and estimation of liquid consumption: implications for research protocol standards definition and for public health authorities' regulation. Int J Environ Res Public Health 2013; 10:2500-2514.

10. McRobbie H, Bullen C, Hartmann-Boyce J et al. Electronic cigarettes for smoking cessation and reduction. Cochrane Database of Systematic Reviews 2014; 12:102-116.

11. Cahill K, Stead L. Lancaster T. Nicotine receptor partial agonists for smoking cessation. Cochrane Database of Systematic Reviews 2012; 4:61:73. a recent study that evaluated middle school and high school students.

A recent report in the New England Journal of Medicine suggests that e-cigarettes stimulate the teen smokers to use more dangerous drugs and act as "gateway for the drugs," like cocaine, marijuana, tobacco, alcohol. ENC serve as an alternative to smoking, a way for users to kick their habit of smoking. Despite claims by manufacturers of their safety the Food and Drug Administration (FDA) has banned the imports of ENC. The Canadian authorities also clamp down the import of these electronic devices in their country.

\section{CONCLUSION}

On the basis of no combustion technique in the use of ENC, these devices are comparatively much less harmful than conventional cigarettes. Because the use of vaporization process in ENC avoid the threat from many toxic chemicals. Indeed existing evidences also indicates that many harmful chemicals are also released in the ENC vapors. This advanced method of inhaling nicotine is also addictive to the same level as that of conventional cigarettes. So it is advised to the health care professional not to recommend ENC as primary cessation tool. But simultaneously the use of ENCs is recommended to the patients only as substitute of conventional cigarettes or to prevent frequent smoking relapse.

12. Stead L, Perera R, Bullen C et al. Nicotine replacement therapy for smoking cessation. Cochrane Database of Systematic Reviews 2012; 14(11):CD000146.

13. National Institute for Clinical Excellence (NICE) Tobacco: harm-reduction approaches to smoking (2013). London: NICE. Available from: https://www.nice.org.uk/guidance/ph45 (accessed 1 December 2015).

14. Etter JF. Electronic cigarettes: a survey of users. BMC Public Health 2010; 10:231.

15. Pepper JK \& Brewer NT. Electronic nicotine delivery system (electronic cigarette) awareness, use, reactions and beliefs: a systematic review. Tob Control 2014; 23(5):375-384.

16. Vansickel AR, Eissenberg T. Electronic cigarettes: effective nicotine delivery after acute administration. Nicotine \& Tobacco Research 2013; 15:267-270.

17. Bullen C, McRobbie H, Thornley S et al. Effect of an electronic nicotine delivery device (e-cigarette) on desire to smoke and withdrawal, user preferences and nicotine delivery: randomised cross-over trial.Tob Control 2010; 19:98-103.

18. Dawkins L, Turner J, Hasna S et al. The electronic-cigarette: effects on desire to smoke, withdrawal symptoms and cognition. Addict Behav 2012; 37:970-973.

19. Etter JF, Bullen C. Electronic cigarette: users profile, utilization, satisfaction and perceived efficacy.Addiction 2011; 106:2017-2028.

20. Vansickel AR, Cobb CO, Weaver MF et al. A clinical laboratory model for evaluating the acute effects of electronic "cigarettes": nicotine delivery profile and cardiovascular and subjective effects.Cancer Epidemiology, Biomarkers \& Prevention 2010; 19(8):1945-1953.

21. Vansickel AR, Weaver MF \& Eissenberg T.Clinical laboratory assessment of the abuse liability of an electronic cigarette. Addiction 2012; 107(8):1493-1500.

22. Polosa R, Caponnetto P, Morjaria JB et al. Effect of an electronic nicotine delivery device (e-cigarette) on smoking reduction and cessation: a prospective 6-month pilot study. BMC Public Health2011; 11:786.

23. Siegel MB, Tanwar KL, Wood KS. Electronic cigarettes as a smoking-cessation: tool results from an online 
survey. American Journal of Preventive Medicine 2011; 40:472-475.

24. Bullen $\mathrm{C}$, Howe $\mathrm{C}$, Laugesen $\mathrm{M}$ et al. Electronic cigarettes for smoking cessation: a randomised controlled trial. Lancet 2013; 382:1629-1637.

25. Foulds J, Veldheer S, Berg A. Electronic cigarettes (e-cigs): views of aficionados and clinical/public health perspectives. Int J Clin Pract 2011; 65:1037-1042.

26. Jensen RP, Luo W, Pankow JF et al. Hidden formaldehyde in e-cigarette aerosols. N Engl J Med 2015; 372:392-394.

27. Public Health England. E-cigarettes: An evidence update (2015). London: Public Health England. Available from: www.gov.uk/government/publications/e-cigarettesan-evidence-update

28. Konstantinos E. Farsalinos and Riccardo Polosa Safety evaluation and risk assessment of electronic cigarettes as tobacco cigarette substitutes: a systematic review, Therapeutic Advances in Drug Safety 2015; 5:67-87.

29. Etter JF, Bullen C. Saliva cotinine levels in users of electronic cigarettes. European Respiratory Journal 2011; 38:1219-1220.

30. Nutt DJ, Phillips LD, Balfour D et al. Estimating the harms of nicotine-containing products using the MCDA approach. European Addiction Research 2014; 20:218225.
31. American Lung Association statement on e-cigarettes. ALA website. lung.org/our-initiatives/tobacco/oversight-andregulation/statement-on-e-cigarettes.html. Updated March 2015. Accessed December 17, 2016.

32. Drug facts: electronic cigarettes (e-cigarettes). National Institute on Drug Abuse website. drugabuse.gov/sites/default/files/drugfacts_ecigs_9_15.pdf. Published August 2015. Updated August 2015. Accessed October 18, 2015.

33. Summary of results: laboratory analysis of electronic cigarettes conducted by FDA. FDA website. www.fda.gov/NewsEvents/PublicHealthFocus/ucm173146 .htm. Updated April 22, 2014. Accessed October 20, 2016.

34. Myths and facts about E-cigarette. American Lung Association website. lung.org/stop-smoking/smokingfacts/myths-and-facts-about-e-cigs.html. Accessed September 17, 2016.

35. Barrington-Trimis JL, Samet JM, McConnell R. Flavorings in electronic cigarettes: an unrecognized respiratory health hazard? JAMA. 2014; 312(23):2493-2494.

36. E-cigarette use among non-cigarette smoking youth triples [press release]. Washington, DC: American Lung Association; August 25, 2014 lung.org/aboutus/media/press-releases/e-cigarette-use-triples-innonsmokinr-youth.html. Accessed September 17, 2016. 